\title{
Endothelin mediates pulmonary vascular remodelling in a canine model of chronic embolic pulmonary hypertension
}

\author{
H. Kim**, G.L. Yung*, J.J. Marsh*, R.G. Konopka*, C.A. Pedersen*, P.G. Chiles*, \\ T.A. Morris*, R.N. Channick*
}

\begin{abstract}
Endothelin mediates pulmonary vascular remodelling in a canine model of chronic embolic pulmonary hypertension. H. Kim, G.L. Yung, J.J. Marsh, R.G. Konopka, C.A. Pedersen, P.G. Chiles, T.A. Morris, R.N. Channick. C ERS Journals Ltd 2000.

ABSTRACT: It is well known that endothelin (ET)-1 mediates vascular remodelling in various kinds of clinical and experimental pulmonary hypertension. The aim of this study was to investigate whether ET-1 is associated with the development of pulmonary vascular remodelling in a canine model of chronic embolic pulmonary hypertension.

Pulmonary hypertension was induced in 10 mongrel dogs by repeated embolization with ceramic beads. In five of the dogs, bosentan, a nonselective ET receptor antagonist, was administered throughout the study. Haemodynamic measurements and plasma ET-1 assays were performed every 2 months. Eight months after initial embolization, computer-assisted morphometry and immunohistochemistry were performed on the lung tissue including that from three control dogs.

Pulmonary arterial pressure and pulmonary vascular resistance were increased in all embolized dogs, compared to baseline. In nontreated embolized dogs, plasma ET-1 concentration and pulmonary arterial wall thickness were increased compared to control animals, and ET-1 immunoreactivity was detected in thickened pulmonary arteries. In bosentan treated dogs, pulmonary arterial walls were not significantly thickened.

Pulmonary vascular remodelling, associated with elevated plasma endothelin-1 levels and positive endothelin-1 immunoreactivity in lung tissue is attenuated by the endothelin receptor antagonist, bosentan. These findings suggest that endothelin mediates pulmonary vascular remodelling in a canine model of chronic embolic pulmonary hypertension.

Eur Respir J 2000; 15: 640-648
\end{abstract}

*Division of Pulmonary and Critical Care
Medicine, Dept of Medicine, University of
California San Diego School of Medicine,
San Diego, California, USA. **Dept of
Medicine, Sungkyunkwan University
School of Medicine, Seoul, Korea.

Correspondence: H. Kim, Pulmonary and Critical Care Medicine, Samsung Medical Centre, 50 Ilwon-dong, Kangnam-ku, Seoul, Korea. Fax: 82234103849

Keywords: Bosentan

chronic thromboembolic pulmonary

hypertension

immunohistochemistry

morphometry

postobstructive pulmonary vasculopathy

Received: June 151999

Accepted after revision January 62000

This study was partly supported by National Institutes of Health (NIH) Institutional Training Grant 5T32 HL-07022-23.
There is increasing evidence that remodelling occurs in the pulmonary vascular bed of patients with chronic thromboembolic pulmonary hypertension (CTEPH) and may contribute to the progression of the disease [1-5]. The mechanisms responsible for this remodelling are, however, poorly understood.

Endothelin (ET)-1 is a potent endogenous vasoconstrictor in the pulmonary circulation and also a growth factor in the pulmonary vasculature [6]. These constrictor and proliferative responses are mainly mediated by $\mathrm{ET}_{\mathrm{A}}$ receptors $[7,8]$, and blocked by selective and nonselective antagonists $[9,10]$. Previous studies have shown that ET-1 is upregulated in the lungs of primary and secondary pulmonary hypertensive patients [11-13], and ET antagonists have been shown to attenuate the development of pulmonary vascular remodelling and pulmonary hypertension $(\mathrm{PH})$ in various animal models [14-16]. In the CTEPH, however, the role of ET-1 is still unclear.

Using a canine model of thromboembolic $\mathrm{PH}$, which the authors have previously developed $[17,18]$, this study was performed to: 1) see whether pulmonary vascular remodelling occurs in a canine model of chronic embolic pulmonary hypertension (CEPH); 2) examine the changes of ET-1 in association with the development of CEPH; and 3) evaluate the effects of bosentan, a nonselective ET receptor antagonist, on pulmonary vascular remodelling in CEPH.

\section{Material and methods}

\section{Study animals}

A total of 10 mongrel dogs (body weight $19-23 \mathrm{~kg}$ ) were used to make the canine CEPH model described below (CEPH dogs), and were studied in parallel with three healthy control dogs. The protocol was approved by the Animal Subjects Committee of the University of California, San Diego, USA, and the procedures followed, were in accord with institutional guidelines.

\section{Animal model}

Animals were anaesthetized by intravenous propofol injection (6-10 $\mathrm{mg} \cdot \mathrm{kg}$ body weight $\left.{ }^{-1}\right)$, intubated, and the endotracheal tube was connected to a respirator equipped 
with a halothane vapourizer. Anaesthesia was maintained with halothane $(1-2 \%)$ with room air and ventilation was adjusted to keep arterial blood gas within normal limits $\left(\mathrm{pH}>7.35\right.$, arterial oxygen tension $\left(\mathrm{Pa}_{\mathrm{a}} \mathrm{O}_{2}\right)>90 \mathrm{mmHg}$ $(>12 \mathrm{kPa})$, arterial carbon dioxide tension $\left(\mathrm{Pa}_{\mathrm{a}} \mathrm{CO}_{2}\right) 35 \pm 5$ $\mathrm{mmHg}(4.7 \pm 0.7 \mathrm{kPa}))$. A femoral arterial catheter $(20$ gauge angiocath catheter; Becton Dickinson, Sandy, UT, USA) was inserted percutaneously and systemic arterial pressure (SAP) was monitored continuously (HewlettPackard 77542B System, Hewlett-Packard Co., USA). The left external jugular vein was cannulated ( $8 \mathrm{~F}$ angiosheath; Cordis Corp., Miami, FL, USA) for blood sampling and the right external jugular vein was cannulated (14F angiosheath; Universal Medical Group, Ballston Spa, NY, USA) percutaneously for pulmonary artery catheterization and embolization.

Thirty minutes after the animals were stabilized, baseline SAP, pulmonary artery pressure (PAP), pulmonary capillary wedge pressure (PCWP) and central venous pressure were measured. Cardiac output $(\mathrm{CO})$ was measured using a thermodilution technique using a flow-directed pulmonary artery catheter (Swan-Ganz catheter, Baxter Healthcare, Irvine, CA, USA) and a cardiac output computer (Edwards COM-2; Baxter Healthcare). Pulmonary vascular resistance (PVR) was calculated by the equation; $\mathrm{PVR}=($ mean PAP $-\mathrm{PCWP}) / \mathrm{CO}$.

Blood samples $(5 \mathrm{~mL})$ were obtained from both the femoral artery and main pulmonary artery (mixed venous) and collected into vacutainer tubes containing $0.057 \mathrm{~mL}$ of $0.34 \mathrm{M}$ ethylenediamine tetraacetic acid (tripotassium salt) and 2,500 KIU of aprotinin. The blood was centrifuged immediately $(2,500 \times \mathrm{g}$, for $15 \mathrm{~min})$ at $4^{\circ} \mathrm{C}$ and plasma was stored at $-70^{\circ} \mathrm{C}$ for ET-1 assay.

To induce embolic pulmonary hypertension (EPH), ceramic beads ( $3.0 \mathrm{~mm}$ in diameter) were introduced one by one into the pulmonary arteries via the right jugular 14F angiosheath catheter (Universal Medical Group). Arterial blood gas and PVR were measured intermittently and bead introduction was continued until either the $\mathrm{Pa}, \mathrm{O}_{2}$ dropped to $<70 \mathrm{mmHg}(<9.3 \mathrm{kPa})$, or the PVR increased to $>500$ dynes $\cdot \mathrm{s}^{-1} \cdot \mathrm{cm}^{-5}$.

After induction of EPH, all catheters were removed and cannulated sites were compressed for haemostasis. Animals were allowed to recover from anaesthesia, extubated, and returned to a vivarium until the next study day.

Table 1. - Mean pulmonary arterial pressure (PAP) before and immediately after ceramic bead embolization in chronic embolic pulmonary hypertensive (CEPH) dogs with/without bosentan

\begin{tabular}{lccccc}
\hline & \multicolumn{2}{c}{ CEPH } & & & \multicolumn{2}{c}{ CEPH+bosentan } \\
\cline { 2 - 3 } \cline { 5 - 6 } & Before & After & & Before & After \\
\hline $\mathrm{n}$ & 5 & 5 & 5 & 5 \\
Day 0 (1st embolization) & $12 \pm 1$ & $23 \pm 1$ & & $13 \pm 1$ & $22 \pm 1$ \\
2 weeks & $15 \pm 1$ & $23 \pm 2$ & & $16 \pm 1$ & $22 \pm 1$ \\
1 month & $18 \pm 1$ & $23 \pm 2$ & & $17 \pm 1$ & $23 \pm 1$ \\
2 months & $18 \pm 1$ & $25 \pm 1$ & & $16 \pm 1$ & $24 \pm 1$ \\
4 months & $18 \pm 1$ & ND & & $18 \pm 1$ & ND \\
\hline
\end{tabular}

Values, expressed in $\mathrm{mmHg}$, are presented as mean $\pm \mathrm{SEM}$. Repeated embolization were needed to sustain chronically elevated PAP. ND: not done. $1 \mathrm{mmHg}=0.133 \mathrm{kPa}$.
Five of the $10 \mathrm{CEPH}$ dogs were treated with bosentan (Hoffman-Roche Ltd., Basel, Switzerland) (CEPH+bosentan group). Bosentan was administered (100 mg.kg body weight $^{-1} \cdot$ day $\left.^{-1}\right)$ orally, mixed in 4-6 oz $(113-170 \mathrm{~g})$ of canned dog food throughout the entire experimental period, starting 7 days before initial embolization.

\section{Repeat embolization and haemodynamic measurements}

Repeat embolizations were performed in all CEPH dogs 2, 4, and 8 weeks after initial embolization to keep PAP elevated, because PAP decreased to $15-18 \mathrm{mmHg}, 2$ weeks after each embolization (table 1). At each time point, bead embolization was ceased according to the algorithm described in the previous section.

Haemodynamic measurements and blood sampling were performed at 2 weeks, and then 1, 2, 4, 6 and 8 months after initial embolization. These were carried out prior to embolization when performed on the same day.

After the final embolization, a pulmonary angiogram was obtained by injecting $20 \mathrm{~mL}$ of $50 \%$ Hypaque (Nycomed Inc., Princeton, NJ, USA) through a Berman catheter (Arrow Inc., Reading, PA, USA) into the right or left main pulmonary artery. At the conclusion of the study ( 8 months after the initial embolization), a lung perfusion scan was obtained with ${ }^{99 \mathrm{~m}} \mathrm{Tc}$-macroaggregated albumin. The animals were then sacrificed and the lungs removed for further study.

\section{Tissue preparation}

After en bloc removal of the heart and lung, the left lower lobe was isolated and the bronchus and main vessels were cannulated. After gently inflating the left lower

Table 2. - Age, body weight, number of beads introduced, and haemodynamic parameters of chronic embolic pulmonary hypertensive (CEPH) dogs with/without bosentan

\begin{tabular}{|c|c|c|c|c|}
\hline & \multicolumn{2}{|c|}{$\mathrm{CEPH}$} & \multicolumn{2}{|c|}{$\mathrm{CEPH+bosentan}$} \\
\hline & Basal & 8 months & Basal & 8 months \\
\hline $\mathrm{n}$ & 5 & 5 & 5 & 5 \\
\hline Age months & $9 \pm 1$ & $17 \pm 1$ & $9 \pm 1$ & $17 \pm 1$ \\
\hline Body weight $\mathrm{kg}$ & $21 \pm 1$ & $23 \pm 1$ & $20 \pm 1$ & $23 \pm 1$ \\
\hline Beads introduced & 0 & $64 \pm 7$ & 0 & $61 \pm 8$ \\
\hline $\begin{array}{l}\text { Mean PAP } \\
\mathrm{mmHg}\end{array}$ & $12 \pm 1$ & $17 \pm 1 * * *$ & $13 \pm 1$ & $17 \pm 1 * * *$ \\
\hline $\begin{array}{l}\text { PVR } \\
\text { dynes } \cdot \mathrm{s}^{-1} \cdot \mathrm{cm}^{-5}\end{array}$ & $177 \pm 12$ & $343 \pm 30 * * *$ & $203 \pm 14$ & $317 \pm 51^{*}$ \\
\hline $\begin{array}{l}\text { Mean SAP } \\
\mathrm{mmHg}\end{array}$ & $82 \pm 6$ & $83 \pm 6$ & $81 \pm 5$ & $85 \pm 4$ \\
\hline PCWP mmHg & $6 \pm 1$ & $8 \pm 1$ & $7 \pm 1$ & $9 \pm 1$ \\
\hline $\begin{array}{l}\text { Cardiac output } \\
\mathrm{L} \cdot \mathrm{min}^{-1}\end{array}$ & $2.7 \pm 0.2$ & $2.2 \pm 0.1$ & $2.3 \pm 0.2$ & $2.1 \pm 0.1$ \\
\hline $\begin{array}{l}\text { Cardiac index } \\
\mathrm{mL} \cdot \mathrm{min}^{-1} \cdot \mathrm{kg}^{-1}\end{array}$ & $127 \pm 18$ & $98 \pm 17$ & $113 \pm 26$ & $91 \pm 14$ \\
\hline$P \mathrm{a}, \mathrm{O}_{2} \mathrm{mmHg}$ & $97 \pm 2$ & $93 \pm 3$ & $97 \pm 3$ & $93 \pm 3$ \\
\hline
\end{tabular}

Data are presented as mean \pm SEM. PAP: pulmonary artery pressure; PVR: pulmonary vascular resistance; SAP: systemic artery pressure; PCWP: pulmonary capillary wedge pressure; $\mathrm{Pa}, \mathrm{O}_{2}$ : arterial oxygen pressure. $*: \mathrm{p}<0.05 ; * * *: \mathrm{p}<0.005$ compared to corresponding basal value. Basal values of CEPH and CEPH+ bosentan dogs were not significantly different $(p>0.05)$. 1 $\mathrm{mmHg}=0.133 \mathrm{kPa}$. 

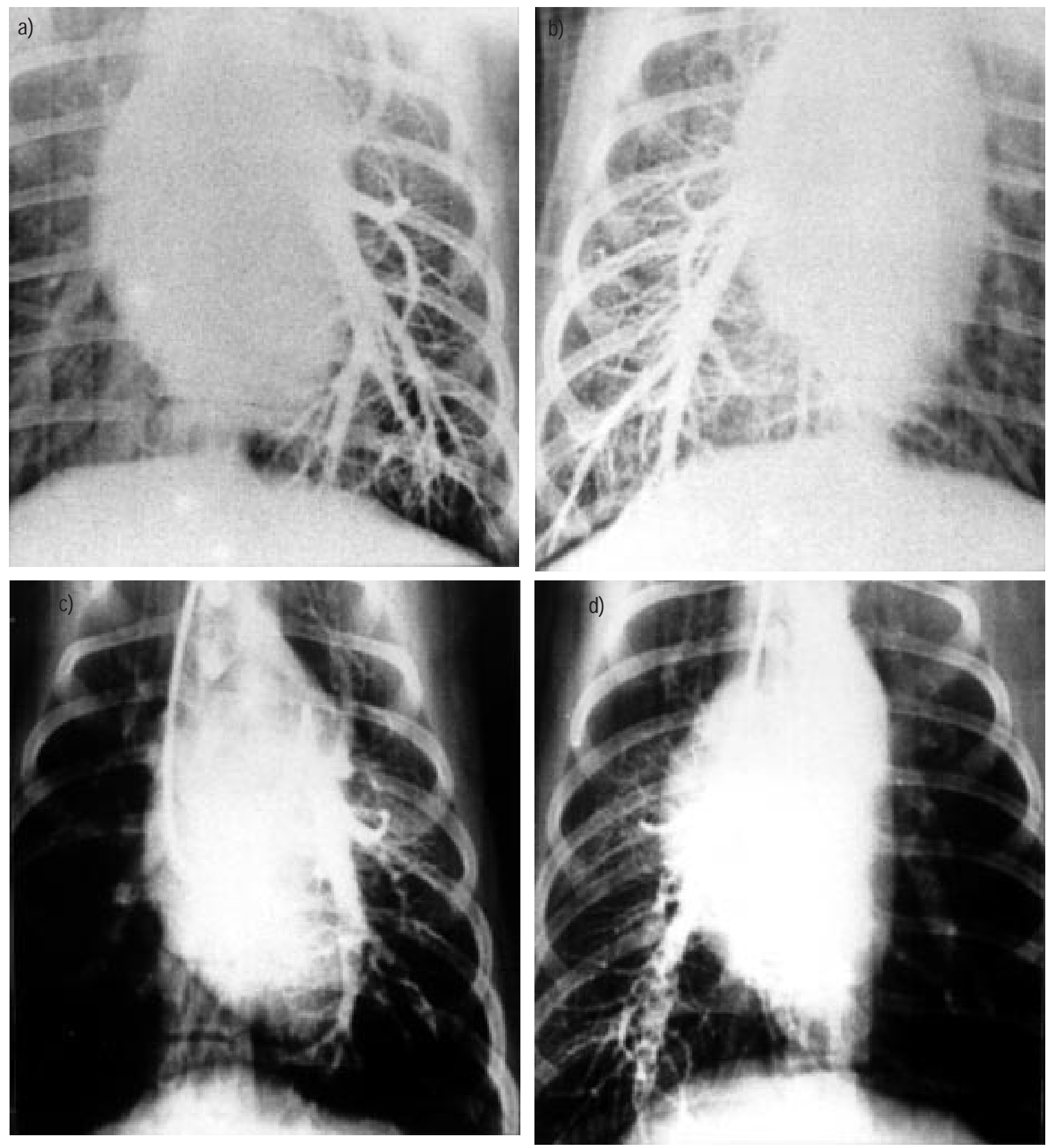

Fig. 1. - A representative pulmonary angiogram of healthy (a and b) and chronic embolic pulmonary hypertensive (CEPH) dog (c and d) obtained after last embolization. Multiple round defects were seen in both lower pulmonary arteries in CEPH dogs.

lobe with atmospheric air, the bronchus was ligated. The pulmonary artery was flushed with saline at $20 \mathrm{cmH}_{2} \mathrm{O}$ pressure, and then the left lower lobe airways were infused with Bouin's solution (Sigma, St. Louis, MO, USA). After overnight fixation at $4^{\circ} \mathrm{C}$, a mid-saggital section was embedded in paraffin for histology.

\section{Microscopy and morphometry}

Combined Masson's trichrome-elastic staining was performed on $5 \mu \mathrm{m}$ thick sections of lung tissue and morphometric measurements were carried out by computer-assisted image analysis (Scion Image, Frederick, MD, USA). Pulmonary arteries were categorized according to size: 25-50, 51-100, 101-200, 201-400, 401-600 and $601-800 \mu \mathrm{m}$ in external diameter (ED). Approximately ten vessels per size category per animal were evaluated by investigators without prior knowledge of the experimental groups. The shortest and longest external diameter, perimeter of internal elastic laminae, and areas within internal and external laminae, luminal margin, and outer margin of adventitia were measured. The cross sectional areas of 
a)

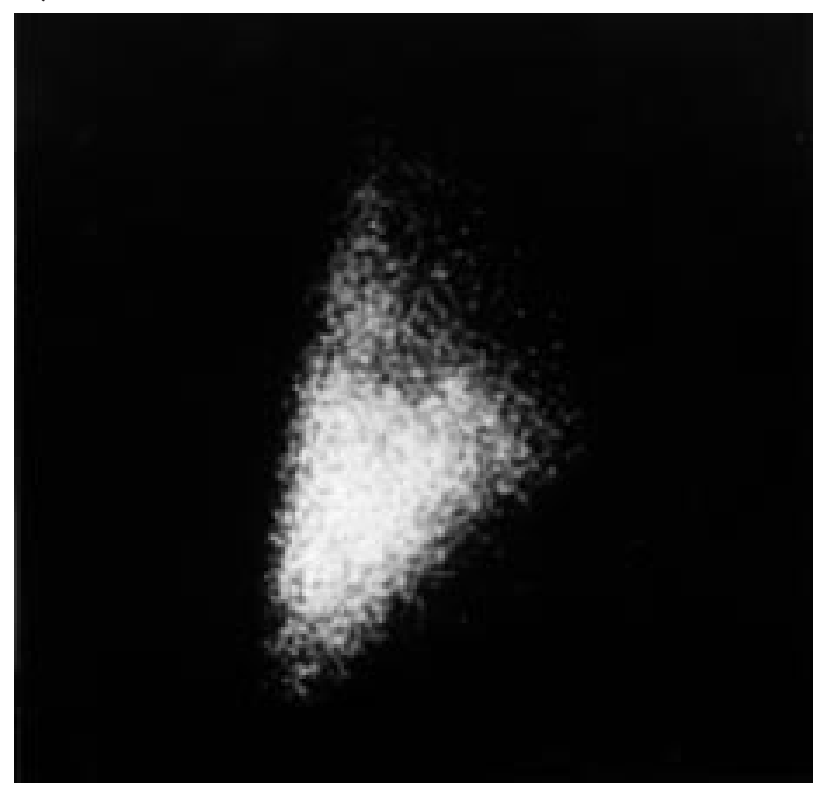

C)

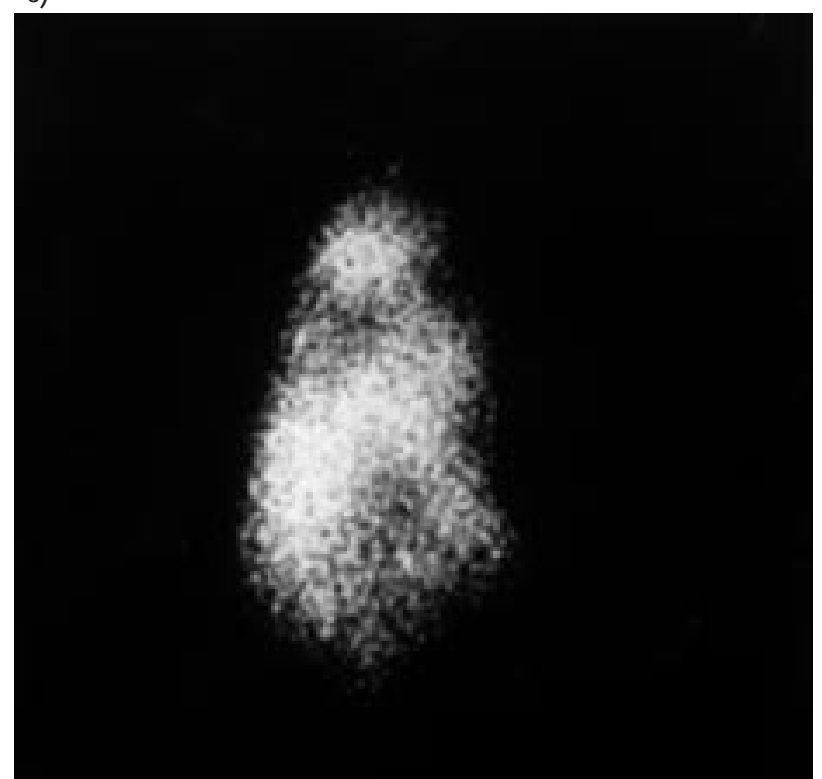

b)

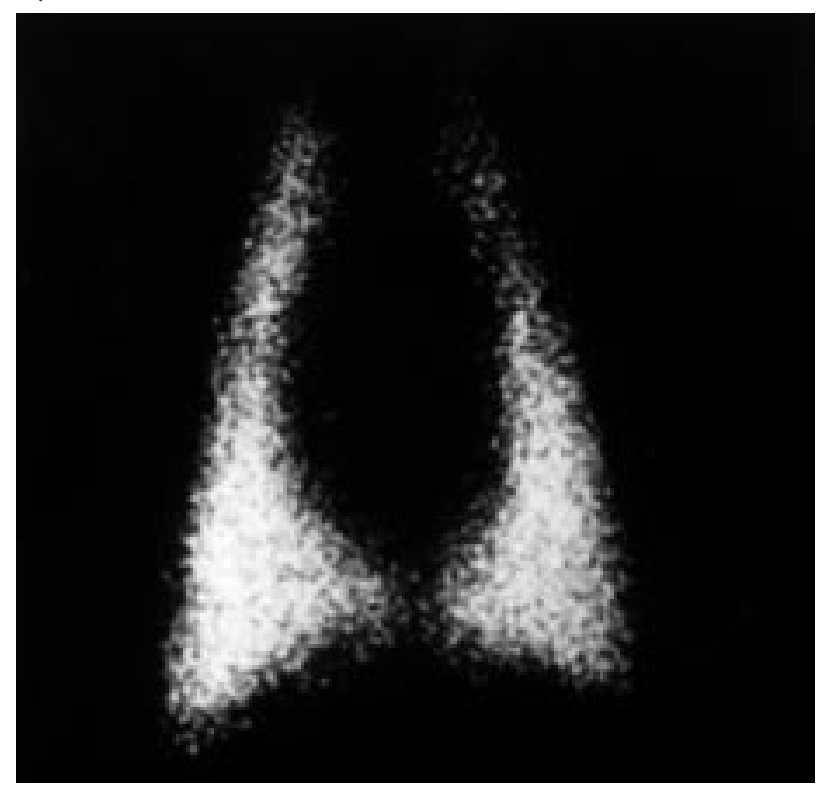

d)

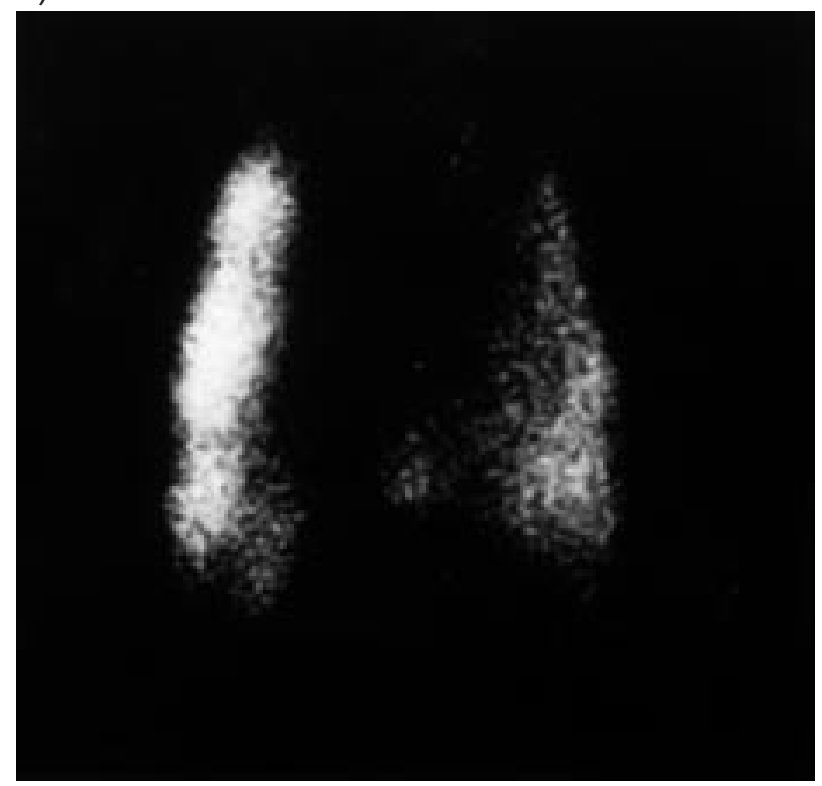

Fig. 2. - A representative lung perfusion scan ( $\mathrm{a}$ and c, anterior posterior view, b and d, left lateral view) of healthy (a and b) and chronic embolic pulmonary hypertensive (CEPH) dog (c and d) obtained at the conclusion of the study ( 8 months after initial embolization). Multiple segmental perfusion defects were visible in lung scans of CEPH dogs.

muscle, adventitia, and intima were calculated by subtracting the inner area from the outer area respectively. Vessel data were then mathematically corrected for oblique cut and post mortem vasoconstriction [19, 20]. From these measurements, ED, medial muscular thickness (MT), adventitial thickness (AT), and intimal thickness (IT) were calculated. Per cent MT (\%MT), AT (\%AT), and IT (\%IT) were computed as $2 \times$ MT (or AT, IT) $\times 100 /$ ED respectively as previously described [21].

\section{Immunohistochemical analysis}

Polyclonal antibody raised against the C-terminal end of human ET-1 (Peptide Institute, Osaka, Japan) was used in the immunohistochemical analysis of lung sections according to the avidin-biotin-peroxidase method [22].

Briefly, sections were deparaffinized in xylene, hydrated with decreasing concentrations of ethanol, washed in 0.05 $\mathrm{M}$ Tris buffer ( $\mathrm{pH} 7.4$ ) containing $0.1 \mathrm{M}$ sodium chloride, and blocked with $10 \%$ normal goat serum overnight at $4{ }^{\circ} \mathrm{C}$. Primary antibody $(1: 1000)$, biotinylated secondary antibody, and streptavidin-peroxidase conjugate were sequentially applied and colour was developed using diaminobenzidine. Negative controls were prepared with the primary antibody absorbed with human ET-1, or by using non-immune serum instead of the primary antibody.

The density of muscle staining in pulmonary vessels and airways was graded semiquantitatively from 0 (absence of 
staining) to 3 (maximal staining). The grading was performed by two investigators without prior knowledge of the experimental groups, and $\sim 10$ vessels per size category per animal were evaluated.

\section{Endothelin-1 immunoassay}

The ET-1 immunoassay was performed in nontreated CEPH dogs using a commercial kit (Cayman Chemical, Ann Arbor, MI, USA) according to the manufacturer's instructions. Briefly, $100 \mu \mathrm{L}$ of plasma extracted by $\mathrm{C}-18$ reverse phase chromatography, was incubated in antibodyprecoated wells with $100 \mu \mathrm{L}$ acetylcholinesterase-Fab' conjugate overnight at $4^{\circ} \mathrm{C}$. After washing five times, $200 \mu \mathrm{L}$ Ellman's Reagent (Cayman Chemical) was added to the wells, and the colour reaction was allowed to proceed for $3 \mathrm{~h}$. Optical absorbance at $405 \mathrm{~nm}$ was read in a Microplate Reader (Molecular Devices Co, Sunnyvale, CA, USA), and the ET-1 concentration of samples was calculated from a standard curve.

\section{Statistical analysis}

All values are presented as mean \pm SEM. Statistical analyses were performed using a two-way analysis of repeated measurements and one-way analysis of variance and Dunnett's and impaired Student's t-tests were carried out to confirm the statistical difference, which was considered significant for $\mathrm{p}<0.05$.

\section{Results}

\section{Documentation of chronic embolism}

A total of $64 \pm 7$ and $61 \pm 8$ beads were introduced to induce CEPH in untreated and bosentan treated CEPH dogs respectively (table 2). Of the total beads used in both groups, $\sim 60 \%$ were given during the first embolization and another $20 \%$ were given during the second embolization.

The pulmonary angiograms obtained after the last embolization, showed multiple round defects in both lower pulmonary arteries (fig. 1). Multiple segmental perfusion defects were observed in lung perfusion scans at the conclusion of the study ( 8 months after initial embolization; fig. 2).

\section{Haemodynamic parameters}

Compared to baseline, PAP and PVR were significantly elevated 1 month after initial embolization and remained elevated at the conclusion of the study in untreated and bosentan treated CEPH dogs, whereas SAP, PCWP, CO, cardiac index, and $\mathrm{Pa}_{\mathrm{a}} \mathrm{O}_{2}$ were not significantly affected (table 2, fig. 3). There was no significant difference between the untreated and bosentan treated CEPH dogs with regard to the haemodynamic parameters, including PAP and PVR, at any time during the study (fig. 3).

\section{Gross and microscopic morphology}

In both untreated and bosentan treated CEPH dogs, ceramic beads were found throughout the main, lobar and segmental pulmonary arteries. The beads were tightly attached to the vascular wall by thick fibrous capsules. The pulmonary arteries proximal to beads were not different either in size or wall thickness compared to control arteries. Distal to the beads, however, muscular hypertrophy,
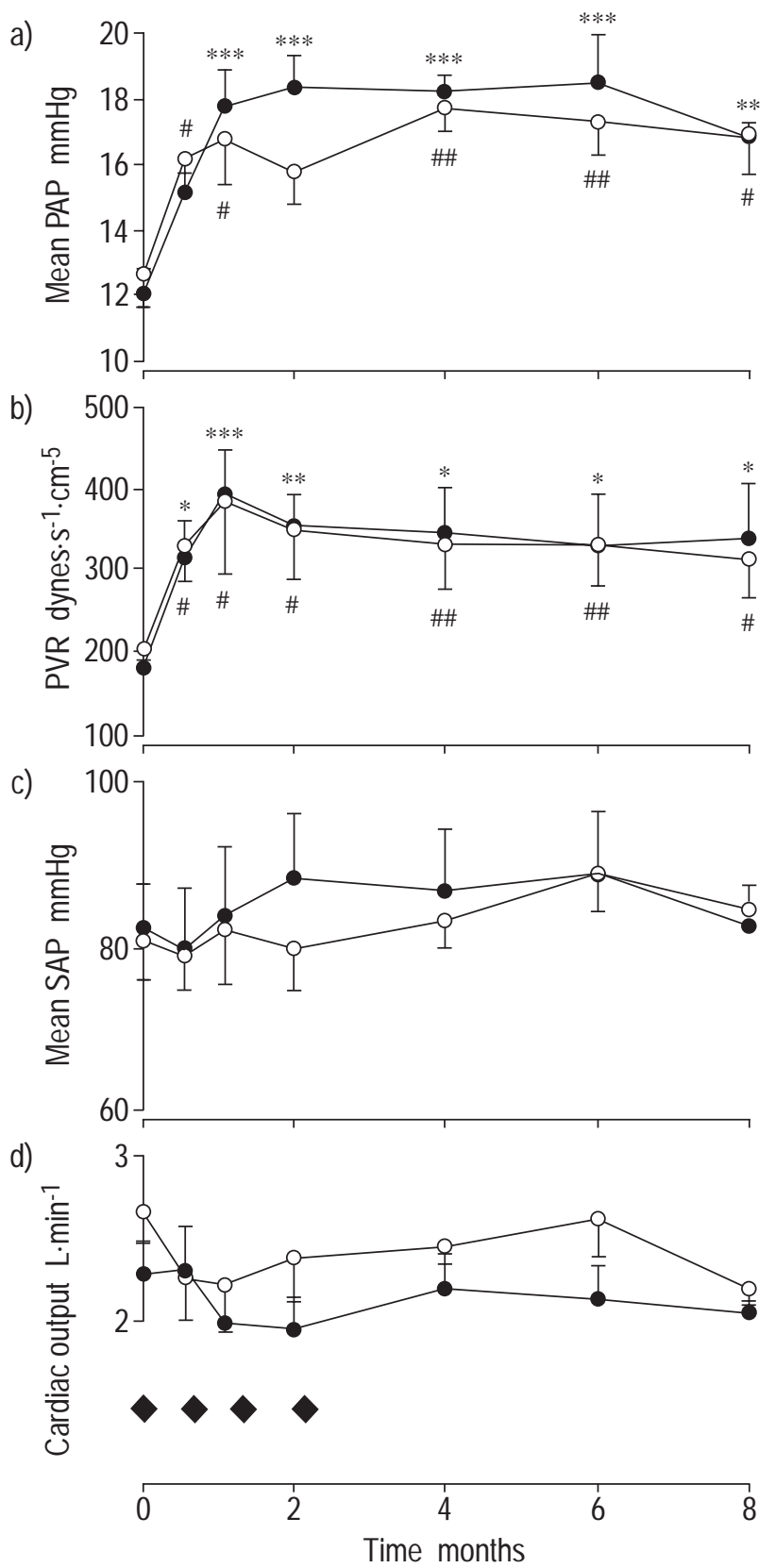

Fig. 3. - Haemodynamic changes over time. Mean pulmonary arterial pressure (PAP; a) and pulmonary vascular resistance (PVR; b) were increased from baseline values by repeated embolization $(\checkmark)$ in both untreated $(O)$ and bosentan treated $(O)$ chronic embolic pulmonary hypertension $(\mathrm{CEPH})$ dogs. Mean systemic arterial pressure (SAP; $)$ and cardiac output (d) were not significantly affected. Values are presented as means \pm SEM. $*: \mathrm{p}<0.05 ; * *: \mathrm{p}<0.01 ; * * *: \mathrm{p}<0.005$ compared to the baseline value (time $=0$ ) of $\mathrm{CEPH}$ dogs. ${ }^{\#}: \mathrm{p}<0.05$; $: \mathrm{p}<0.01$ compared to the baseline value (time $=0$ ) of $\mathrm{CEPH}+$ bosentan dogs. 

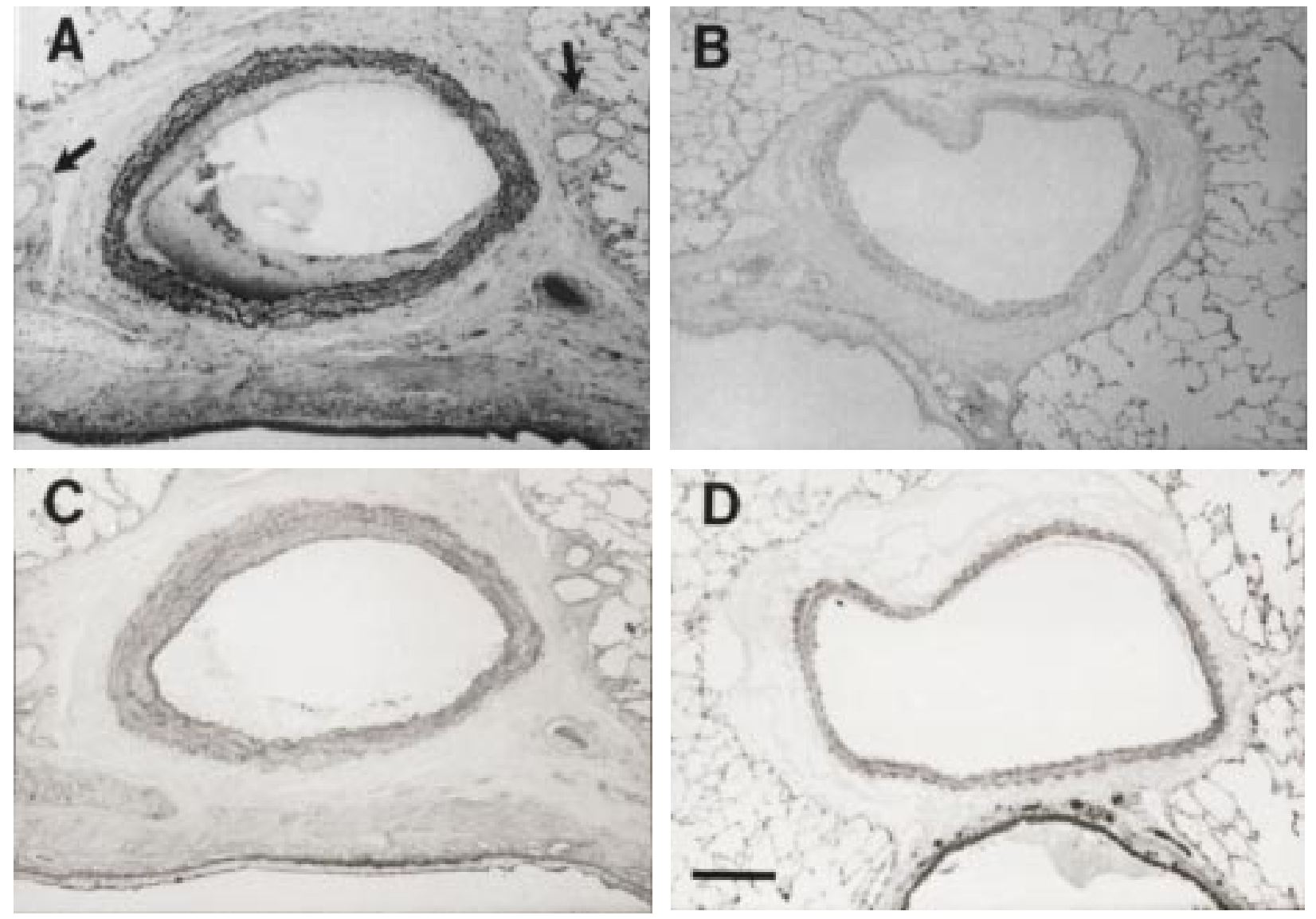

Fig. 4. - A) Muscular layer of pulmonary arteries was thickened and bronchial arteries (arrows) were markedly increased in size and number in chronic embolic pulmonary hypertension (CEPH) dogs (Trichrome staining). (B-D) 1/1,000 endothelin (ET)-1 immunostaining of untreated CEPH (C), bosentan treated CEPH (D), and control dogs (B). ET-1 immunoreactivity was noted in the vascular smooth muscle cells and endothelium of untreated CEPH (C) and bosentan treated CEPH dog lungs (D), whereas no immunoreactivity was detected in control lungs (B). Internal scale bar=200 $\mu$ m.

eccentric intimal fibrosis, and peripheral muscularization were found in untreated CEPH (fig. 4A), but not in bosentan treated CEPH dog lungs. Proliferation of bronchial arteries was also observed around bronchi and pulmonary vessels in CEPH dog lungs (arrows in fig. 4A).

\section{Pulmonary artery morphometry}

As shown in figure 5, pulmonary arteries of bosentan treated dogs were not significantly different from control animals with respect to \%MT, \%AT, and \%IT. In contrast, untreated CEPH dogs had significantly higher \%MT (in all but 25-50 $\mu \mathrm{m}$ pulmonary arteries) and \%AT (201-600 $\mu \mathrm{m}$ pulmonary arteries) compared to control animals. Per cent MT (201-600 $\mu \mathrm{m}$ pulmonary arteries) and \%AT (401-600 $\mu \mathrm{m}$ pulmonary arteries) were significantly lower in bosentan treated compared to untreated CEPH dogs.

\section{Immunohistochemistry}

Immunoreactivity against ET-1 was observed in vascular smooth muscle cells, endothelial cells, and airway epithelial cells in untreated (fig. 4C) and bosentan treated CEPH dog lungs (fig. 4D), but not in control dogs (fig. 4B). The ET-1 immunoreactivity was most prominent in thickened vascular smooth muscle and endothelial cells of mid-sized $(400-800 \mu \mathrm{m})$ pulmonary arteries, but no
ET-1 immunoreactivity was observed in newly formed bronchial arteries, pulmonary veins, or small $(<100 \mu \mathrm{m})$ pulmonary arteries (fig. 6).

\section{Plasma endothelin-1 concentration}

In untreated CEPH dogs, ET-1 concentrations were significantly increased 4,6 , and 8 months after initial embolization in both mixed venous and arterial plasma compared to baseline (fig. 7). The peak plasma ET-1 level was $3.0 \pm 0.5 \mathrm{pg} \cdot \mathrm{mL}^{-1}$ (mixed venous plasma, 6 months after initial embolization). No significant difference in ET-1 concentration was observed between paired mixed venous and arterial plasma samples in CEPH dogs.

\section{Discussion}

In this study, the authors have demonstrated elevated plasma ET-1 levels, positive ET-1 immunoreactivity, and increased pulmonary arterial muscle thickness in a canine model of CEPH. In addition, the authors have shown that the morphometric changes associated with this pulmonary vascular remodelling are prevented by prolonged administration of bosentan, an orally active, nonselective ET receptor antagonist. These findings suggest that ET-1 plays a specific role in the pulmonary vascular remodelling seen in $\mathrm{CEPH}$. 

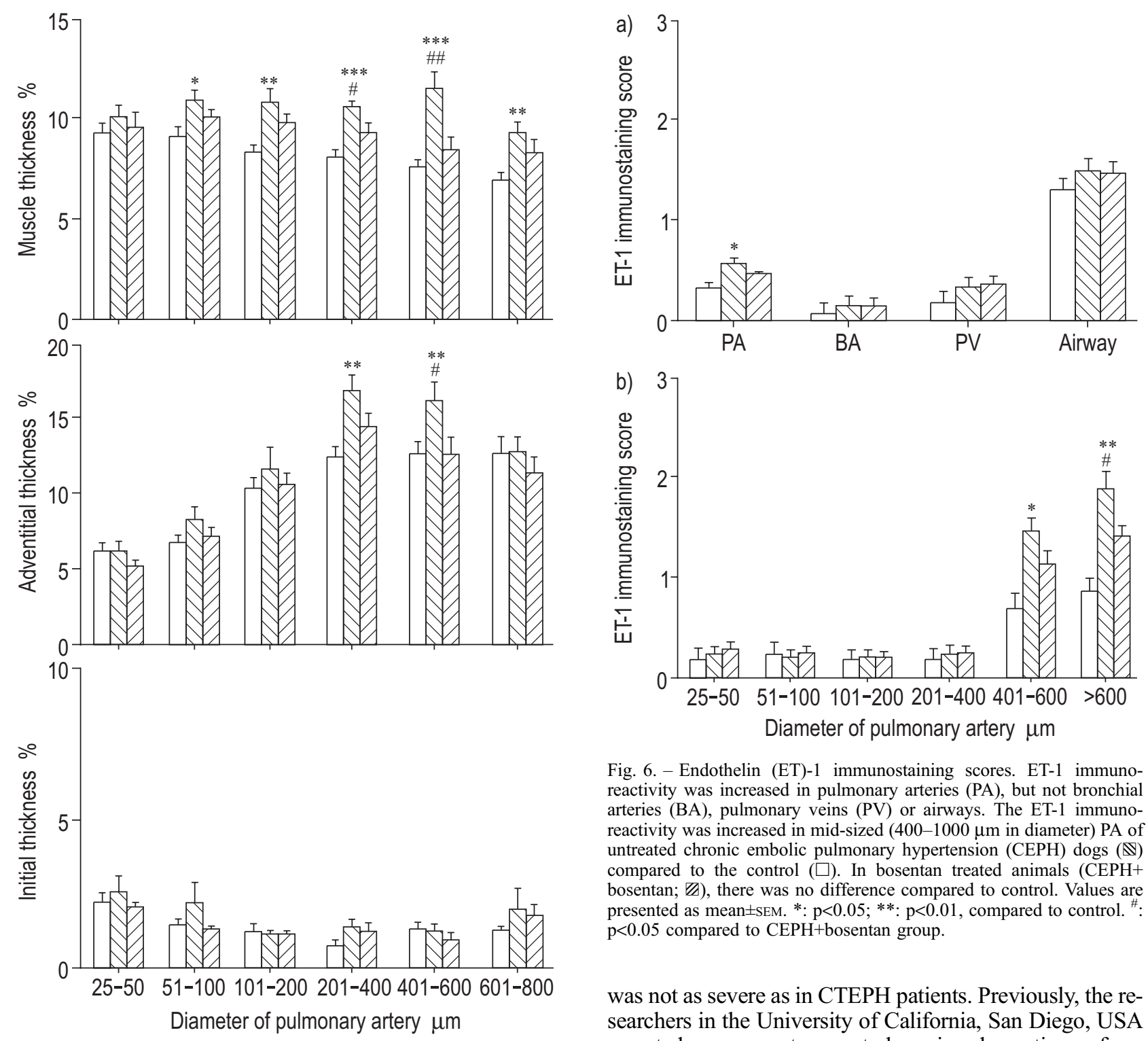

Fig. 6. - Endothelin (ET)-1 immunostaining scores. ET-1 immunoreactivity was increased in pulmonary arteries (PA), but not bronchial arteries (BA), pulmonary veins (PV) or airways. The ET-1 immunoreactivity was increased in mid-sized $(400-1000 \mu \mathrm{m}$ in diameter) PA of untreated chronic embolic pulmonary hypertension $(\mathrm{CEPH}) \operatorname{dogs}(\mathbb{\mathbb { N }})$ compared to the control $(\square)$. In bosentan treated animals (CEPH+ bosentan; $\mathbb{Z}$ ), there was no difference compared to control. Values are presented as mean \pm SEM. $*$ : $\mathrm{p}<0.05 ;{ }^{* *}: \mathrm{p}<0.01$, compared to control. ${ }^{\#}$ : $\mathrm{p}<0.05$ compared to $\mathrm{CEPH}+$ bosentan group.

was not as severe as in CTEPH patients. Previously, the researchers in the University of California, San Diego, USA reported on an autopsy study using lung tissue from patients who died of CTEPH [4]. In this study, the mean antemortem PAP was $48 \pm 12 \mathrm{mmHg}$ (more than three times of normal value), whereas mean PAP in the current model was $\sim 40 \%$ above the basal value $(17 \pm 1$ versus $12 \pm$ $1 \mathrm{mmHg}$, table 2). Likewise, the thickness of the pulmonary vascular muscle layer was $\sim 30 \%$ of the external diameter of the vessel in patients who died of CTEPH (mean muscle mass ratio of muscular arteries was $0.519 \pm 0.319$ ), which is more than twice that observed in this model. Although the maximum number of beads that could be tolerated by the dogs were used, PAP was not as high and pulmonary vascular remodelling was not as substantial as that seen in CTEPH patients.

Although bosentan did not attenuate $\mathrm{PH}$, morphometric parameters of pulmonary vascular remodelling were attenuated in bosentan treated CEPH dogs. In pulmonary circulation, vascular resistance is known to be generated by muscular pulmonary arteries such as those $150-1,000 \mu \mathrm{m}$ in diameter [21, 23]. These "resistant" arteries were remodelled most prominently in untreated CEPH dogs, and the changes were attenuated by bosentan. In addition, 


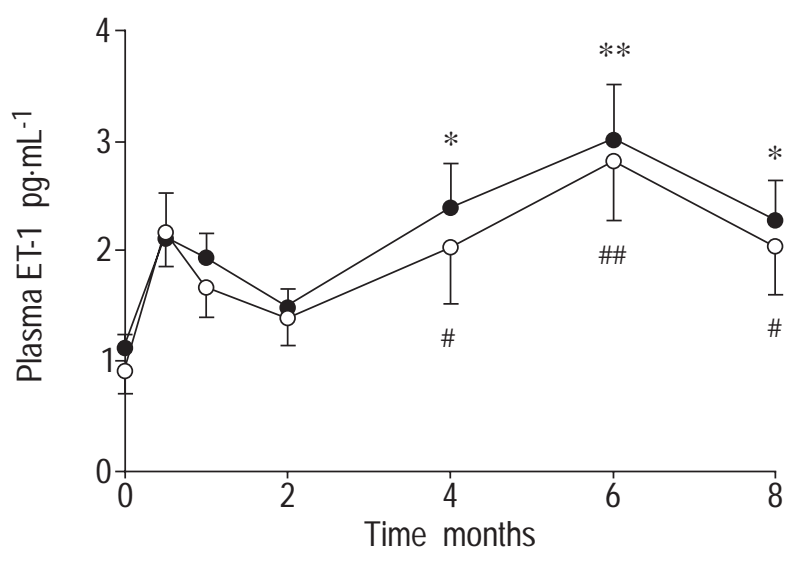

Fig. 7. - Plasma endothelin (ET)-1 changes according to time in untreated chronic embolic pulmonary hypertension (CEPH) dogs. ET-1 concentrations of paired mixed venous $(\mathbf{O})$ and arterial $(O)$ plasma were elevated 4, 6, 8 months after initial embolization. ET-1 concentration was higher in mixed venous plasma than arterial plasma at 1, 2, 4, 6, 8 months after initial embolization. Values are presented as mean \pm SEM. *: $\mathrm{p}<0.05 ; * *: \mathrm{p}<0.01$, compared to mixed venous baseline value. ${ }^{\#}$ : $\mathrm{p}<0.05 ;{ }^{\#}: \mathrm{p}<0.01$, compared to arterial baseline value.

ET-1 immunoreactivity was overexpressed at the site of pulmonary vascular remodelling, i.e. thickened pulmonary vascular smooth muscle cells of "resistant" pulmonary arteries. These findings suggest that vascular remodelling may be mediated by ET-1 in this canine model of CEPH.

What caused vascular remodelling in this model? It is well known that pulmonary vascular remodelling occurs in various kinds of experimental $\mathrm{PH}$, induced by hypoxia [14-16, 23-25], monocrotaline [26], hyperperfusion [27], and in fawn-hooded rats $[28,29]$. In addition, postobstructive pulmonary vasculopathy (POPV) induced by chronic, unilateral pulmonary artery ligation has been shown to cause vascular remodelling [30-32]. Hypoxia could be a cause, but since oxygen rich systemic blood is known to shunt to pulmonary circulation via newly formed bronchial arteries [30, 31], hypoxia is unlikely to have induced vascular changes. In the present study, $\mathrm{Pa}_{\mathrm{a}} \mathrm{O}_{2}$ was always $>85 \mathrm{mmHg}(>11.3 \mathrm{kPa})$ and usually $>90$ $\mathrm{mmHg}(>12 \mathrm{kPa})$ at the time of catheterization (table 3$)$. Hyperperfusion may be the cause of the pulmonary vascular remodelling in the current model. As discussed below, the observed arteries could be either distal to embolization or overperfused vessels in nonembolized lung area. Further investigation is required to document whether hyperperfusion caused vascular changes in this model. Another possible mechanism would be POPV, a unique vascular remodelling seen in the distal part of the obstructive pulmonary vasculature. Though it is not yet clearly understood, POPV has a similar pathology to other kinds of $\mathrm{PH}$ [31].

The plasma ET-1 level was elevated in this study and the level was not significantly different in mixed venous and arterial plasma. The difference between ET-1 concentrations in the mixed venous and arterial plasma may reflect net pulmonary production and clearance across the pulmonary vascular bed. For example, in patients with primary $\mathrm{PH}, \mathrm{ET}-1$ is extraordinarily overproduced in the pulmonary vascular bed. Not only arterial and mixed venous plasma ET-1 levels were elevated, but also the arterial ET-1 level was much higher than the mixed venous level [12]. On the
Table 3. - Arterial oxygen pressure of chronic embolic pulmonary hypertension

\begin{tabular}{lcc}
\hline & \multicolumn{2}{c}{ Arterial oxygen pressure } \\
\cline { 2 - 3 } & CEPH & CEPH+Bosentan \\
\hline $\mathrm{n}$ & 5 & 5 \\
Baseline & $97 \pm 2$ & $97 \pm 3$ \\
2 weeks & $91 \pm 2$ & $88 \pm 4$ \\
1 month & $85 \pm 3$ & $88 \pm 5$ \\
2 months & $91 \pm 2$ & $93 \pm 2$ \\
4 months & $93 \pm 1$ & $92 \pm 5$ \\
6 months & $87 \pm 2$ & $92 \pm 2$ \\
8 months & $94 \pm 3$ & $93 \pm 3$ \\
\hline
\end{tabular}

Values, expressed in $\mathrm{mmHg}$, are presented as mean \pm SEM. 1 $\mathrm{mmHg}=0.133 \mathrm{kPa}$.

other hand, in patients with secondary PH, ET-1 clearance is reduced while the production is normal. In these patients, both arterial and mixed venous plasma ET-1 levels were similarly elevated [12]. Therefore, similarly elevated ET-1 levels in mixed venous and arterial plasma suggest that reduced clearance across the lung, rather than overproduction, may be responsible for the elevated ET-1 levels observed in the current CEPH model.

There are clear limitations to this study. Firstly, immunostaining is mainly qualitative. Although the authors graded ET-1 immunoreactivity semiquantitatively, Western blot analysis, followed by molecular biological techniques, necessary to accurately quantify differences in expression of ET-1 in this model. Secondly, although morphometric changes in peripheral pulmonary arteries were found, the authors could not be certain that the measured arteries were always distal to embolization. They might be overperfused vessels in nonembolized lung areas. Vascular remodelling is known to occur in vessels submitted to increased pressure and/or flow. However, in an animal model of prolonged unilateral pulmonary artery ligation, pulmonary vascular remodelling occurred in vessels distal to the ligated pulmonary artery, but not in contralateral hyperperfused pulmonary arteries [30-32]. Therefore, further studies should follow to investigate where pulmonary vascular remodelling occurs in the CEPH model; distal to embolization or overperfused vessels in the nonembolized lung area. Thirdly, the authors used ceramic beads instead of thrombi for embolization. Previously the authors have developed a canine model of thromboembolic PH by repetitive embolization of venous thrombi induced in vivo $[17,18]$. Because the efficient fibrinolytic system of the canine made it difficult to retain thrombi for a long period of time (even with concomitant administration of the fibrinolytic inhibitor, tranexamic acid), the authors chose to use ceramic beads for this 8-month study. Although ceramic beads induced PH by mechanical obstruction, there might be additional responses between thrombi and vascular wall, if thrombi induced in vivo could be used.

Nevertheless, this model closely parallels a clinical condition, CTEPH [3, 4]. There is increasing evidence that vascular remodelling has a major influence on the progression of PH in CTEPH patients over time [1-5]. In some CTEPH patients with unilateral pulmonary artery occlusion, nonreperfusion was reported even after removal of extensive chronic thromboembolic material [5]. If 
the ET- 1 changes described in the current study are also present in these patients, potential treatments to modify or reverse the lesion would be possible.

In conclusion, pulmonary vascular remodelling associated with elevated plasma endothelin-1 concentration and positive endothelin-1 immunoreactivity was attenuated by the endothelin receptor antagonist, bosentan. These findings may suggest that endothelin mediates pulmonary vascular remodelling in this canine model of chronic embolic pulmonary hypertension.

Acknowledgements. The authors acknowledge K.M. Moser for inspiration and encouragement. The authors wish to thank Hoffman-Roche Ltd (Basel, Switzerland) for generously supplying the bosentan.

\section{References}

1. Moser KM, Auger WA, Fedullo PF. Chronic major vessel thromboembolic pulmonary hypertension. Circulation 1990; 81: 1735-1741.

2. Moser KM, Auger WA, Fedullo PF, Jamieson SW. Chronic thromboembolic pulmonary hypertension: clinical picture and surgical treatment. Eur Respir J 1992; 5: 334-342.

3. Fedullo PF, Auger WR, Channick RN, Moser KM, Janieson SW. Chronic thromboembolic pulmonary hypertension. Clin Chest Med 1995; 16: 353-374.

4. Moser KM, Bloor CM. Pulmonary vascular lesions occurring in patients with chronic major vessel thromboembolic pulmonary hypertension. Chest $1993 ; 103$ : 685692.

5. Hirsch AM, Moser KM, Auger WR, Channick RN, Fedullo PF. Unilateral pulmonary artery thrombotic occlusion: is distal arteriopathy a consequence? Am J Respir Crit Care Med 1996; 154: 491-496.

6. Yanagisawa M. The endothelin system: a new target for therapeutic intervention. Circulation 1994; 89: 1320-1322.

7. Arai $\mathrm{H}$, Hori $\mathrm{H}$, Aramori I, Ohkubo H, Nakanishi S. Cloning and expression of a cDNA encoding an endothelin receptor. Nature 1990; 348: 730-732.

8. Barnes PJ, Liu SF. Regulation of pulmonary vascular tone. Pharmacol Rev 1995; 47: 87-131.

9. Ferro CJ, Webb DJ. The clinical potential of endothelin receptor antagonists in cardiovascular medicine. Drugs 1996; 51: 12-27.

10. Tamirasa P, Frishman WH, Kumar A. Endothelin and endothelin antagonism: roles in cardiovascular health and disease. Am Heart $J$ 1995; 130: 601-610.

11. Giaid AG, Yanagisawa M, Langleben D, et al. Expression of endothelin-1 in the lungs of patients with pulmonary hypertension. N Engl J Med 1993; 328: 1732-1739.

12. Stewart DJ, Levy RD, Cernacek P, Langleben D. Increased plasma endothelin-1 in pulmonary hypertension: marker or mediator of disease? Ann Int Med 1991; 114: 464-469.

13. Yamakami T, Taguchi O, Gabazza EC, et al. Arterial endothlin-1 level in pulmonary emphysema and interstitial lung disease: relation with pulmonary hypertension during exercise. Eur Respir J 1997; 10: 2055-2060.

14. Oparil S, Chen SJ, Meng QCElton TSYano MChen Y. Endothelin-A receptor antagonist prevents acute hypoxiainduced pulmonary hypertension in the rat. Am J Physiol 1995; 268: L95-L100.

15. Eddahibi S, Raffestin B, Clozel M, Levame M, Adnot S.
Protection from pulmonary hypertension with an orally active endothelin receptor antagonist in hypoxic rats. $\mathrm{Am}$ $J$ Physiol 1995; 268: H828-H835.

16. Okada M, Yamashita C, Okada K. Endothelin receptor antagonists in a beagle model of pulmonary hypertension: contribution to possible potential therapy? $\mathrm{J} \mathrm{Am} \mathrm{Coll}$ Cardiol 1995; 25: 1213-1217.

17. Moser KM, Cantor JP, Olman M, et al. Chronic pulmonary thromboemboliism in dogs treated with tranexamic acid. Circulation 1991; 83: 1371-1379.

18. Cantor JP, Graif JL, Konopka RG, Hartman MT, Moser KM. Chronic pulmonary thromboembolism in canines treated with tranexamic acid. Am Rev Respir Dis 1988; 137: $185 \mathrm{~A}$.

19. Fernie J, Lamb D. New method for measuring intimal component of pulmonary arteries. J Clin Pathol 1985; 38 : 1374-1379.

20. Fernie J, Lamb D. New method for quantitating the medial component of pulmonary arteries. Arch Pathol Lab Med 1985; 109: 843-848.

21. Davies P, Reid L, deMello D. Methods in experimental pathology of pulmonary vasculature. In: Gil J, eds. Models of Lung Disease. 1st Edn New York, NY, USA, Marcel Dekker, 1990; pp. 843-904.

22. Hsu S, Raine L, Fanger H. A comparative study of the peroxidase-antiperoxidase method and an avidin-biotin complex method for studying polypeptide hormones with radioimmunoassay antibodies. Am J Clin Pathol 1981; 75: 734-738.

23. Hislop A, Reid L. Changes in the pulmonary arteries of the rat during recovery from hypoxiainduced pulmonary hypertension. Br J Exp Pathol 1977; 58: 653-662.

24. Li H, Elton TS, Chen YF, Oparil S. Increased endothelin receptor gene expression in hypoxic rat lung. $\mathrm{Am} \mathrm{J}$ Physiol 1994; 266: L553-L601.

25. Chen S, Chen Y, Meng QC, Durand J, Dicarlo VS, Opraril S. Endothelin-receptor antagonist bosentan prevents and reverses hypoxic pulmonary hypertension in rats. $J$ Appl Physiol 1995; 79: 2122-2131.

26. Miyauchi T, Yorikane R, Sakai S, et al. Contribution of endogenous endothelin-1 to the progression of cardiopulmonary alterations in rats with monocrotaline-induced pulmonary hypertension. Circ Res 1993; 73: 887-897.

27. Wong J, Reddy VM, Hendricks-Munoz K, Liddicoat JR, Gerrets R, Fineman JR. Endothelin-1 vasoactive responses in lambs with pulmonary hypertension and increased pulmonary blood flow. Am J Physiol 1995; 269: H1965H1972.

28. Zamora MR, Stelzner TJ, Webb S, Panos RJ, Ruff LJ, Dempsey EC. Overexpression of endothelin-1 and enhanced growth of pulmonary artery smooth muscle cells from fawn-hooded rats. Am J Physiol 1996; 270: L101-L109.

29. Stelzner TJ, O'Brien RF, Yanagisawa M, et al. Increased lung endothelin-1 production in rats with idiopathic pulmonary hypertension. Am J Physiol 1992; 262: L614L620.

30. Michel RP, Hakim TS, Petsikas D. Segmental vascular resistance in postobstructive pulmonary vasculopathy. $J$ Appl Physiol 1990; 69: 1022-1032.

31. Michel RP, Hakim TS. Increased resistance in postobstructive pulmonary vasculopathy: structure-function relationships. J Appl Physiol 1991; 71: 601-610.

32. Giaid A, Stewart DJ, Michel RP. Endothelin-1-like immunoreactivity in postobstructive pulmonary vasculopathy. J Vasc Res 1993; 30: 333-338. 